\title{
Synergizing Sulfonated Hydrothermal Carbon and Microwave Irradiation for Intensified Esterification Reaction
}

Laddawan Tumkot ${ }^{1}$, Armando T. Quitain ${ }^{2,3 *}$, Panatpong Boonnoun ${ }^{4}$, Navadol Laosiripojana ${ }^{5}$, Tetsuya Kida ${ }^{2}$, Artiwan Shotipruk ${ }^{1}$

${ }^{1}$ Bio-Circular-Green-Economy Technology \& Engineering Center, BCGeTEC,

Department of Chemical Engineering, Faculty of Engineering, Chulalongkorn University,

$$
\text { Bangkok 10330, Thailand }
$$

${ }^{2}$ Department of Applied Chemistry and Biochemistry, Faculty of Advanced Science and Technology, Kumamoto University, Kumamoto 860-8555, Japan

${ }^{3}$ Center for International Education, Kumamoto University, Kumamoto 860-8555, Japan

${ }^{4}$ Department of Industrial Engineering, Chemical Engineering Program, Faculty of Engineering, Naresuan University, Phitsanulok 65000, Thailand.

${ }^{5}$ The Joint Graduate School of Energy and Environment, King Mongkut's University of Technology-Thonburi Prachauthit Road, Bangmod, Bangkok 10140, Thailand 


\section{Supporting Information}

(a) Oleic to MeOH 1:10

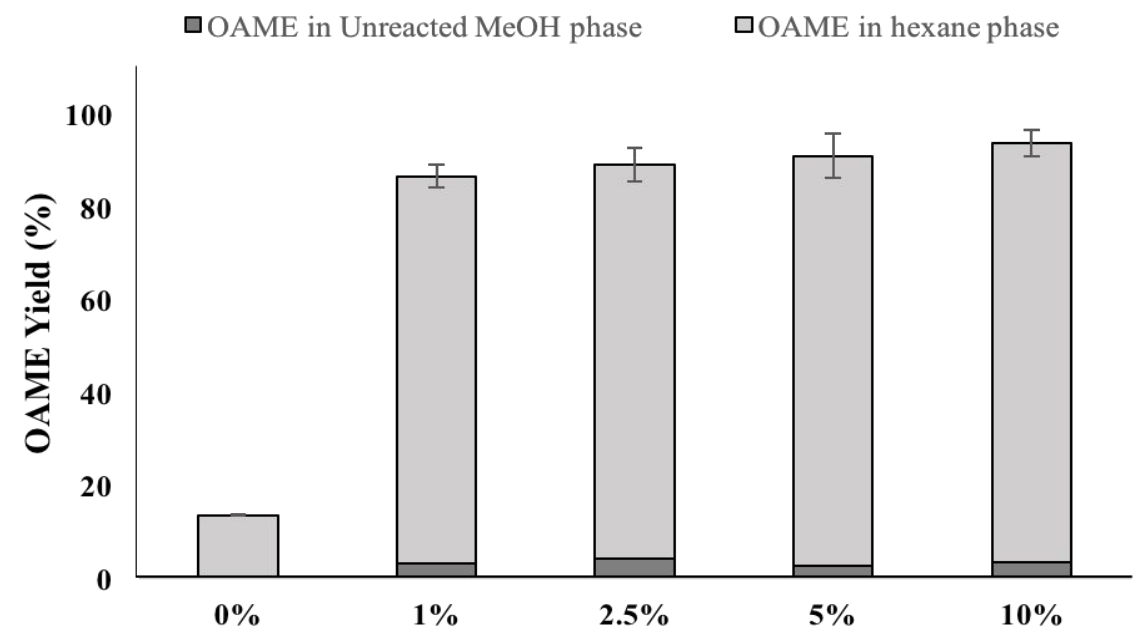

(b) Oleic to MeOH 1:25

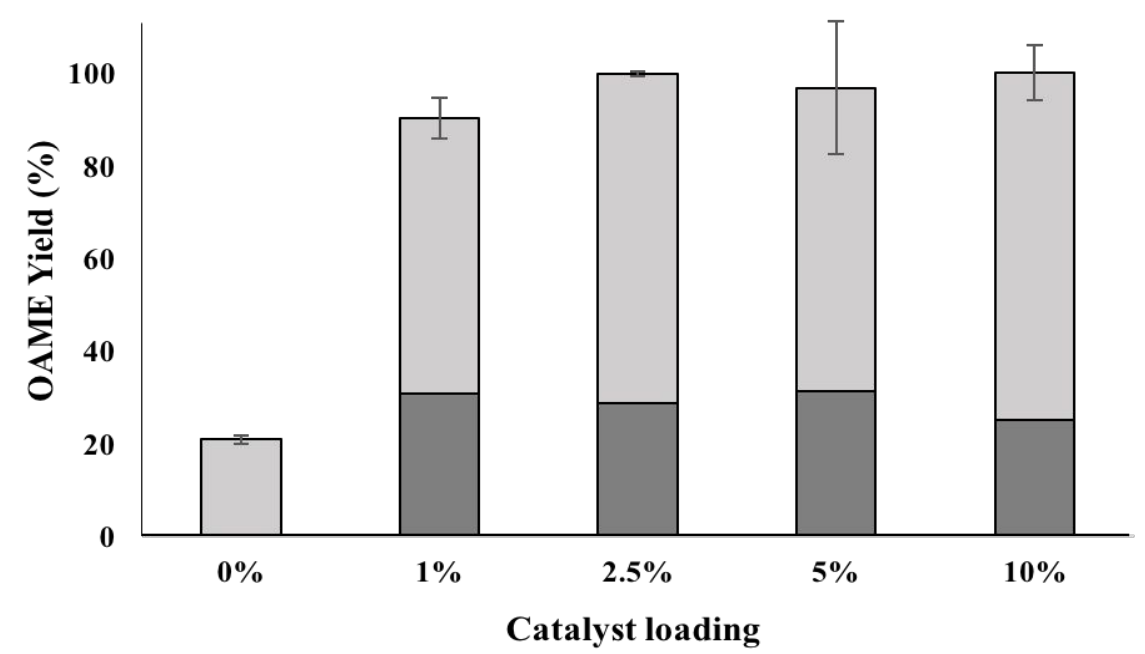

Figure S1. Effect of different oleic to methanol ratio (a) 1:10 (b) 1:25 on catalyst loading. [Conditions: $\mathrm{T}=100^{\circ} \mathrm{C}, 60 \mathrm{~min}, \mathrm{H} / \mathrm{M}=1.8(\mathrm{v} / \mathrm{v})$ ] 


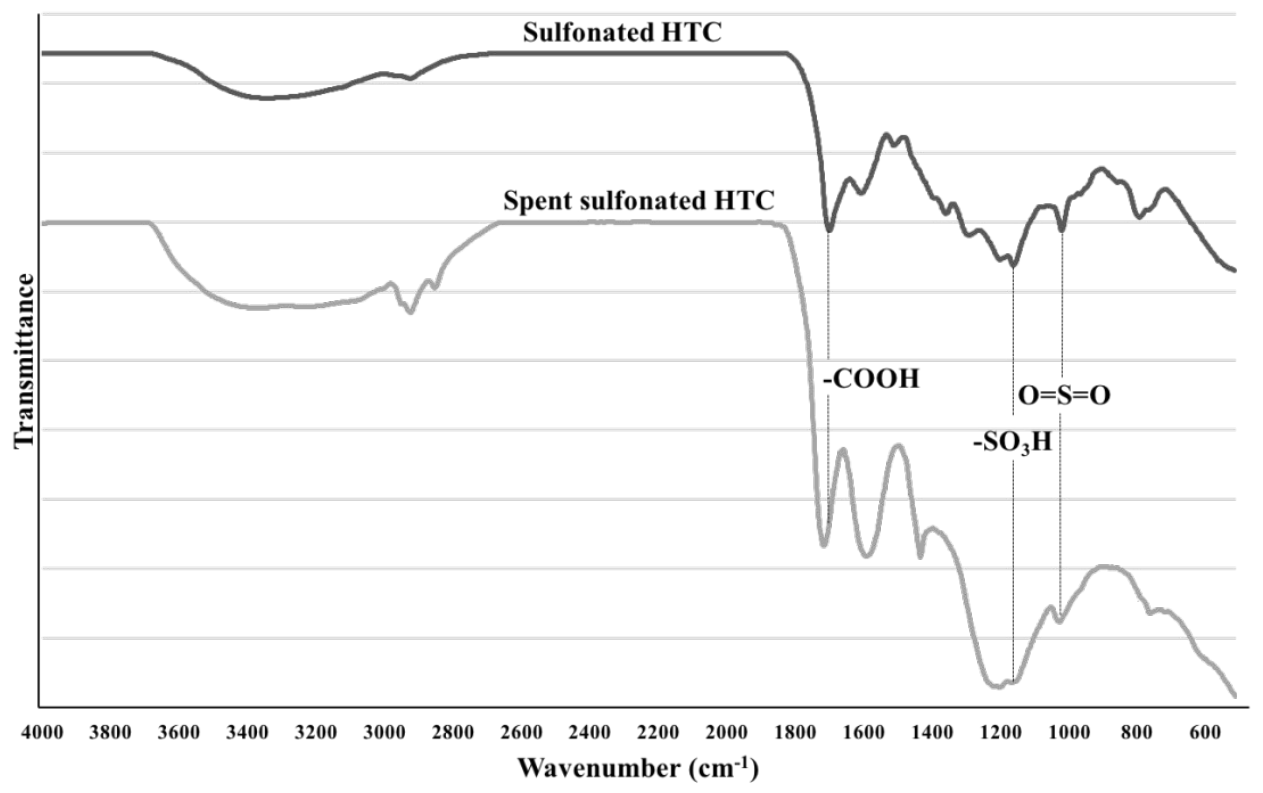

Figure S2. FT-IR spectra of the sulfonated HTC and spent sulfonated HTC after 5 cycles in esterification. 